\title{
HEALTHCARE ASSOCIATED DEEP PELVIC TISSUE INFECTION AND OTHER INFECTIONS OF THE FEMALE REPRODUCTIVE TRACT IN UKRAINE
}

DOI: $10.36740 /$ WLek202103105

\author{
Aidyn G. Salmanov' ${ }^{1}$, Lidiya V. Suslikova', Svitlana A. Pandei' , Victor O. Rud², Igor V. Kokhanov' ${ }^{1}$ Victoria Ye. Butska', \\ Alexander G. Tymchenko' \\ 'SHUPYK NATIONAL HEALTHCARE UNIVERSITY OF UKRAINE, KYIV, UKRAINE \\ 2NATIONAL PIROGOV MEMORIAL MEDICAL UNIVERSITY, VINNYTSIA, UKRAINE
}

\begin{abstract}
The aim: To obtain the first estimates of the current prevalence of healthcare-associated deep pelvic tissue infection and other infections of the female reproductive tract (vagina, ovaries, uterus) including chorioamnionitis, and antimicrobial resistance of causing pathogens in Ukraine.

Materials and methods: We performed a retrospective multicenter cohort study was based on surveillance data. The study population included 3,053 women's who underwent gynecological surgery or other procedures from 2017 to 2019 in 7 women hospitals in Ukraine. Definitions of healthcare-associated reproductive tract infection were used from the CDC/ NHSN. Results: The prevalence of healthcare-associated deep pelvic tissue infection and other infections of the female reproductive tract was $26.3 \%$. Incidence of infection was: 13.3\% Pelvic abscess or cellulitis, 14.6\% Adnexa utery, 9.5\% Salpingitis, 7.1\% 0ophoritis, 12.2\% Parametritis, 4.6\% Chorioamnionitis, and 38.8\% Bacterial Vaginitis. The predominant pathogens were: Escherichia coli (25.6\%), Enterobacter spp. (11.4\%), Klebsiella pneumoniae (10.6\%), Staphylococcus aureus (8.5\%), Enterococcus faecalis (7.2\%) and Pseudomonas aeruginosa (7.1\%). Methicillin-resistance was observed in $14.3 \%$ of $S$. aureus (MRSA). The overall proportion of extended spectrum beta-lactamases (ESBL) production among Enterobacteriaceae was $20.8 \%$. The prevalence of ESBL production among E. coli isolates was $24.7 \%$ and among K. pneumoniae $11.9 \%$. Resistance to thirdgeneration cephalosporins was observed in $12.8 \%$ E.coli and $9.2 \%$ K. pneumoniae isolates.

Carbapenem resistance was identified in $8.5 \%$ of P.aeruginosa isolates.

Conclusions: Healthcare associated deep pelvic tissue infection and other infections of the female reproductive tract in Ukraine is a common occurrence and many cases are caused by pathogens that are resistant to antibiotics.
\end{abstract}

KEY WORDS: Healthcare-associated infection, deep pelvic tissue infection, female, vagina, ovaries, uterus, chorioamnionitis, pathogens, antimicrobial resistance

Wiad Lek. 2021;74(3 p.l):406-412

\section{INTRODUCTION}

Healthcare-associated reproductive tract infection (HARTI) in female is a major problem for public health care in worldwide, causing increased morbidity and mortality in women. These infections may result in infertility, ectopic pregnancy and chronic pelvic pain and other disease [14]. The prevalence of RTIs in women varies from country to country and ranges from $1.8 \%$ [5] to $48 \%$ [6,7]. In the United States, 1 million women are diagnosed with RTI each year and the cost of their treatment is estimated at \$ 4.2 billion [8]. Many studies show that despite the introduction into medical practice of new diagnostic technologies for diagnosis and treatment, as well as broad-spectrum antibiotics, the number of healthcare-associated infections is not decreasing.

HARTIs in female include Endometritis, Episiotomy, Vaginal cuff infections and other infections of the female reproductive tract [9]. Other infection of the female reproductive tract involves the Deep pelvic tissue infection or other infection of the female reproductive tract (for example, vagina, ovaries, uterus) including chorioamnionitis, but excluding Endometritis or Vaginal cuff infections [9]. In the available literature, there are many studies devoted to Endometritis or Vaginal cuff infections. However, there are a limited number of studies on other reproductive tract infection in female.

One of the reasons for healthcare-associated infections is the wide spread of conditionally pathogenic microorganisms in Ukraine that are resistant to antibiotics $[10,11]$. The emergence and spread of antimicrobial resistance has become a major public health threat in Ukraine, and the number of infections caused by resistant pathogens causing of HARTIs continues to increase $[12,13]$.

Antimicrobial resistance creates obstacles for effective prevention and treatment of patients with infections. Every year resistant healthcare-associated infection is becoming more and more pressing for medical specialists in Ukraine. Microbiological monitoring of the prevalence of etiologic agents of HARTIs and antimicrobial resistance is necessary to enhance our knowledge of its epidemiology. To our knowledge, the prevalence of and causative agents of most HARTIs (besides Endometritis and Episiotomy infections) 
among female in-patients and out patients have not been studies in Ukraine. This was the basis for our study.

\section{THE AIM}

The aim of this study was to obtain the first estimates of the current prevalence of infection of the female reproductive tract involves the Deep pelvic tissue infection or other infections of the female reproductive tract including Chorioamnionitis, but excluding Endometritis or Vaginal cuff infections and antimicrobial resistance of responsible pathogens in Ukraine.

\section{MATERIALS AND METHODS}

\section{SETTING}

We performed a retrospective multicenter cohort study was based on surveillance data of Reproductive Tract Infections in women's from January 1st, 2017 to December 31st, 2019 in 7 regional (tertiary) women hospitals of Ukraine. The hospitals had 1250 beds. They are similar in terms of medical equipment, staff and number of beds. All participating hospitals were required to have at least one full-time infection-control professional, a clinical microbiology laboratory with the capacity to process cultures.

\section{PARTICIPANTS}

Inclusion criteria: This study included 3,053 women's aged 16-55 years admitted to hospitals with the diagnosis of acute pelvic inflammatory disease (PID). All women were local residents. Diagnosis of acute PID was based on criteria from the Centers for Disease Control and Prevention (CDC) [4].

Exclusion criteria: endometritis or vaginal cuff infections; current pregnancy; positive serological test for syphilis or other sexually transmitted infections; inflammatory bowel disease or significant renal or hepatic disease; had a history of colitis; neoplasms or haematological malignancy.

\section{DEFINITIONS OF HARTI}

Diagnosis of Deep pelvic tissue infection or other infection of the female reproductive tract (vagina, ovaries, uterus) including chorioamnionitis was based on criteria from the CDC/NHSN Surveillance Definitions for Specific Types of Infections [9]. Women had uterine curettage, or delivery, abortion, instrumentation of the upper genital tract, pelvic or abdominal surgery within the last month (30 days) prior to admission.

\section{DATA COLLECTION}

In this study, we analyzed the inpatient data and ambulatory medical records to identify deep pelvic tissue infection or other infections of the female reproductive tract including chorioamnionitis. We collected the data using structured
NHSN Reproductive Tract Infection (REPR) Checklist. Full-text ambulatory medical records and relevant hospital records were reviewed for the all women's. Additional data form was created to extract demographic and clinical data, microbiology (isolated pathogens and antibiograms) and outcome information from inpatient data and ambulatory medical records.

\section{MICROBIOLOGICAL METHODS}

All samples were obtained from women with clinical symptoms of PID. Microbial isolates were identified using standard microbiological techniques, including automated microbiology testing (Vitek-2; bioMe'rieux, Marcy l'Etoile, France). Antibiotic susceptibility testing was performed by using the disk diffusion method (Kirby - Bauer antibiotic testing) according to the recommendations of the European Committee on Antimicrobial Susceptibility Testing (EUCAST). Strains in the intermediate range were classified as resistant for data analysis.

\section{ETHICS}

The Shupyk National Medical Academy of Postgraduate Education of Ukraine ethics committee approved the waiver of informed consent to participate in this study due to its retrospective design. All pregnant women's data were anonymised prior to the analysis.

\section{STATISTICAL ANALYSIS}

Prevalence of healthcare-associated deep pelvic tissue infection or other infections of the female reproductive tract was reported as the percentage of the total number of women who had been submitted to PID cases. We analyzed samples from women's in the context of a study about microbiology of HARTI and antimicrobial resistance of responsible pathogens. The analysis of statistical data was performed using Excel. Results are expressed as median (range), mean standard deviation for continuous variables, and number and corresponding percentage for qualitative variables. Comparisons were undertaken using Student's t-test and Fisher's exact test for categorical variables. Statistical significance was defined as $P<0.05$.

\section{RESULTS}

\section{PREVALENCE AND TYPE OF INFECTION}

During the study period (from 2017 to 2019), 804 of 3,053 patients were found to have healthcare-associated infections (HAI). The prevalence of healthcare-associated deep pelvic tissue infection and other infections $(n=804)$ of the female reproductive tract in women hospitals in Ukraine was $26.3 \%$ [95\% confidence interval (CI) 25.5-27.1]. Of these cases, 13.3\% Pelvic abscess or cellulitis, 14.6\% Adnexa utery, 9.5\% Salpingitis, 7.1\% Oophoritis, $12.2 \%$ Parametritis, $4.6 \%$ Chorioamnionitis, and $38.8 \%$ Bacterial Vaginitis 
were identified (Table I). Of 804 cases healthcare-associated deep pelvic tissue infection and other infections of the female reproductive tract, $78.6 \%$ were detected after hospital discharge. None of the patients died as a result of these infections. The prevalence of healthcare-associated deep pelvic tissue infection and other infections of the female reproductive tract in women differed according to the procedure types. Gynecologic patients had a higher incidence of healthcare-associated deep pelvic tissue infection and other infections of the female reproductive tract compared with pregnant women. The largest number of cases were identified after Abortion (35.8\%, 95\% CI 34,1 - 37.5), Instrumentation of the upper genital tract (20.1\%, 95\% CI $18,7-21.5)$ and vaginal surgery (19.4\%, $95 \%$ CI $18,0-20.8)$. The incidence of HAI was $10.9 \%$ after abdominal surgery, $8.3 \%$ after laparoscopic surgery, and $5.3 \%$ after delivery (Table II). Vaginal delivery represented a low risk of HAIs compared cesarean delivery.

A total of 3053 women in reproductive age ( $16-55$ years) participated in the study. The median age of the women was 28 years. The proportion of healthcare associated deep pelvic tissue infection and other infections of the female reproductive tract was higher in divorced $(37.9 \%)$ than marred women (14.4\%). Demographic and Social characteristics of patients with healthcare associated deep pelvic tissue infection and other infections of the female reproductive tract in Ukraine are presented in Table III.

\section{ANTIBIOTIC PROPHYLAXIS}

For Ukraine antibiotic prophylaxis at surgery and gynecological procedure is standard practice. In this study of 3,053 patients with PID who underwent chart review, 3,012 (98.7\%) were prescribed Ceftriaxone (75\%) or Cefotaxime (25\%). However, 804 (26.3\%) of 3,053 patients developed infections of the reproductive tract.

\section{RESPONSIBLE PATHOGENS}

In this study, a total of 1857 pathogens isolated from 804 women with healthcare associated deep pelvic tissue infection and other infections of the female reproductive tract in Ukraine were analyzed using culture based methods. Of these pathogens, gram-negative bacilli make up $73.6 \%$ (1367/1857) and 26.4\% (490/1857) gram-positive cocci from of all isolates. The predominant pathogens of healthcare associated deep pelvic tissue infection and other infections of the female reproductive tract were: Escherichia coli (25.6\%), Enterobacter spp. (11.4\%), Klebsiella pneumoniae (10.6\%), Staphylococcus aureus (8.5\%), Enterococcus faecalis

Table I. Types of healthcare-associated deep pelvic tissue infection and other infections $(n=804)$ of the female reproductive tract in Ukraine $(P<0.05)$

\begin{tabular}{|c|c|c|c|}
\hline \multirow{2}{*}{ HAI $I^{\text {a }}$ type } & \multicolumn{2}{|c|}{ Cases of HAl ${ }^{\mathrm{a}}$} & \multirow{2}{*}{$95 \% \mathrm{Cl}^{\mathrm{b}}$} \\
\hline & $n$ & $\%$ & \\
\hline A pelvic abscess or cellulitis & 107 & 13.3 & $12.1-14.5$ \\
\hline Infection of the uterine appendages (Adnexa utery) & 117 & 14.6 & $13.4-15.8$ \\
\hline Infection of the Fallopian tubes (Salpingitis) & 76 & 9.5 & $8.5-10.5$ \\
\hline Infection of the ovaries (Oophoritis) & 57 & 7.1 & $6.2-8.0$ \\
\hline Infection of the supporting ligaments (Parametritis) & 98 & 12.2 & $11.1-13.3$ \\
\hline Chorioamnionitis & 37 & 4.6 & $3.9-5.3$ \\
\hline Infection of the Vagina (Bacterial Vaginitis) & 312 & 38.8 & $37.1-40.5$ \\
\hline
\end{tabular}

Note

aHAl, healthcare-associated infection

${ }^{\mathrm{b}} \mathrm{Cl}$, confidence interval.

Table II. Distribution of type procedure associated deep pelvic tissue infection and other infections $(n=804)$ of the female reproductive tract in Ukraine

\begin{tabular}{cccc} 
Type of procedure & \multicolumn{2}{c}{ Cases of HAl $^{\mathbf{a}}$} & \multirow{2}{*}{$\mathbf{9 5 \%} \mathbf{C l}^{\mathbf{b}}$} \\
\cline { 2 - 3 } & $\boldsymbol{n}$ & $\mathbf{\%}$ & \\
\hline Surgery & & 10,9 & $9,8-12.0$ \\
\hline Abdominal & 88 & $18,0-20.8$ \\
\hline Vaginal & 156 & $7,3-9.3$ \\
\hline Laparoscopic & 67 & 8,3 & $4,5-6.1$ \\
\hline Delivery (vaginal and cesarean delivery) & 43 & 5,3 & $34,1-37.5$ \\
\hline Abortion & 288 & 35,8 & $18,7-21.5$ \\
\hline Instrumentation of the upper genital tract & 162 & 20,1 & \\
\hline
\end{tabular}

Note

aHAl, healthcare-associated infection

${ }^{b} \mathrm{Cl}$, confidence interval. 
Table III. Demographic and Social characteristics of patients with healthcare associated deep pelvic tissue infection and other infections of the female reproductive tract in Ukraine $(\mathrm{P}<0.05)$

\begin{tabular}{|c|c|c|c|c|}
\hline \multirow[b]{2}{*}{ Variables } & \multirow{2}{*}{$\begin{array}{c}\text { Number of } \\
\text { participants } \\
n\end{array}$} & \multicolumn{2}{|c|}{$\mathrm{HAl}^{\mathbf{a}}$} & \multirow{2}{*}{$95 \% \mathrm{Cl}^{\mathrm{b}}$} \\
\hline & & $n$ & $\%$ & \\
\hline \multicolumn{5}{|l|}{ Age of participants } \\
\hline $16-20$ & 117 & 16 & 13,7 & $13,1-14.3$ \\
\hline $21-25$ & 338 & 71 & 21,0 & $20,3-21.7$ \\
\hline $26-30$ & 417 & 162 & 38,8 & $37,9-39.7$ \\
\hline $31-35$ & 374 & 137 & 36,6 & $35,7-37.5$ \\
\hline $36-40$ & 596 & 144 & 24,2 & $23,4-25.0$ \\
\hline $41-45$ & 488 & 87 & 17,8 & $17,1-18.5$ \\
\hline $46-50$ & 402 & 76 & 18,9 & $18,2-19.6$ \\
\hline $51-55$ & 321 & 111 & 34.6 & $33,7-35.5$ \\
\hline \multicolumn{5}{|l|}{ Marital status } \\
\hline Single & 1578 & 461 & 29,2 & $28,4-30.0$ \\
\hline Married & 918 & 132 & 14,4 & $13,8-15.0$ \\
\hline Divorced & 557 & 211 & 37,9 & $37,0-38.8$ \\
\hline \multicolumn{5}{|l|}{ Residence } \\
\hline Rural & 857 & 112 & 13,1 & $12,5-13.7$ \\
\hline Urban & 2196 & 692 & 31,5 & $30,7-32.3$ \\
\hline \multicolumn{5}{|l|}{ Educational status } \\
\hline College and above & 618 & 137 & 22,2 & $21,5-22.9$ \\
\hline Highs school & 2435 & 667 & 27,4 & $25,6-28.2$ \\
\hline \multicolumn{5}{|l|}{ Occupational status } \\
\hline Employed & 633 & 151 & 23,9 & $23,1-24.7$ \\
\hline Merchant & 675 & 163 & 24,1 & $23,3-24.9$ \\
\hline Students & 421 & 112 & 26,6 & $25,8-27.4$ \\
\hline Unemployed & 1324 & 378 & 28,5 & $27,7-29.3$ \\
\hline Total & 3053 & 804 & 26,3 & $25,5-27.1$ \\
\hline
\end{tabular}

Note

a HAl, healthcare-associated infection

${ }^{\mathrm{b}} \mathrm{Cl}$, confidence interval.

(7.2\%), Pseudomonas aeruginosa (7.1\%). The distribution of microorganisms causing deep pelvic tissue infection and other infections of the female reproductive tract in Ukraine is shown in Table IV.

\section{ANTIMICROBIAL RESISTANCE}

Staphylococcal strains displayed a most resistance to penicillin (78.1\%) and erythromycin (58.7\%). In this study methicillin-resistance was observed in $12.9 \%$ of $S$. aureus (MRSA). However, Staphylococcal isolates showed susceptibility to most of the other antimicrobials tested. No strains resistant to linezolid, teicoplanin, vancomycin, tigecycline, and fusidic acid were found.

Streptococcal isolates demonstrated a noteworthy resistance against erythromycin (54.7\%) and benzylpenicillin (42.3\%), followed by ampicillin (29.8\%). Most of the Streptococcal strains were sensitive to clindamycin $(89.1 \%)$, gentamycin $(93.2 \%)$, cefuroxime $(95.1 \%)$, and linezolid (100\%).

E. faecalis isolates were not sensitive to cefuroxime, clindamycin, and trimethoprim-sulfamethoxazole. Approximately, $20 \%$ of the E. faecalis isolates displayed resistance to aminoglycosides and $11.4 \%$ was resistant to quinolones.

The overall proportion of extended spectrum betalactamases (ESBL) production among Enterobacteriaceae was $20.8 \%$. The prevalence of ESBL production among $E$. coli isolates was $24.7 \%$. E. coli was most sensitive (>90\%) to ertapenem, cefotaxime, ceftazidime, imipenem, piperacillin/tazobactam and high $(>60 \%)$ resistance to cefuroxime, amoxicillin, and levofloxacin. Antimicrobial resistance to third-generation cephalosporins was observed in $12.8 \%$ E.coli isolates.

Isolates of Enterobacter spp. was most sensitive (>90\%) to ciprofloxacin, cefotaxime, piperacillin/tazobactam, 


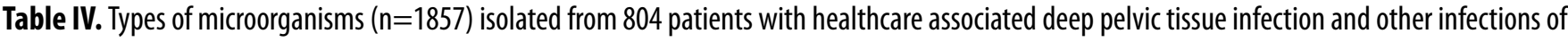
the female reproductive tract in Ukraine

\begin{tabular}{|c|c|c|}
\hline \multirow{2}{*}{ Microrganisma $^{a}$} & \multicolumn{2}{|c|}{ All isolates } \\
\hline & $n$ & $\%$ \\
\hline Gram-positive cocci & 490 & 26.4 \\
\hline Staphylococcus aureus & 157 & 8.5 \\
\hline Enterococcus faecalis & 134 & 7.2 \\
\hline Streptococcus spp. & 112 & 6.0 \\
\hline Staphylococcus epidermidis & 73 & 3.9 \\
\hline Enterococcus faecium & 14 & 0.8 \\
\hline Gram-negative bacilli & 1367 & 73.6 \\
\hline Escherichia coli & 476 & 25.6 \\
\hline Enterobacter spp. & 211 & 11.4 \\
\hline Klebsiella pneumoniae & 197 & 10.6 \\
\hline Pseudomonas aeruginosa & 132 & 7.1 \\
\hline Proteus mirabilis & 112 & 6.0 \\
\hline Acinetibacter spp. & 103 & 5.5 \\
\hline Serratia spp. & 77 & 4.1 \\
\hline Citrobacter spp. & 43 & 2.3 \\
\hline Klebsiella oxytoka & 16 & 0.9 \\
\hline
\end{tabular}

Note:

"Used "The Bergey's Manual of Determinative Bacteriology" 9th Edition

ceftazidime and ticarcillin. No strains of Enterobacter spp. resistant to cefepime, meropenem, imipenem, and ertapenem were found. Enterobacter spp. strains were high (>50\%) resistance to ampicillin/sulbactam, ampicillin, amoxicillin/clavulanic acid, clindamycin, ciprofloxacin, and high percentage resistance to gentamycin $(41.2 \%)$, cefaperazon (38.5\%) and ceftriaxon (29.2\%).

K. pneumoniae isolates showed high susceptibility to piperacillin/tazobactam, ertapenem, meropenem, imipenem, levofloxacin, and gentamycin. However, these stranis while ones exhibited a noticeable percentage $(>30 \%)$ of resistance to ampicillin, amoxicillin/clavulanic acid, ofloxacin, and ciprofloxacin. The prevalence of ESBL production among K. pneumoniae isolates was $11.9 \%$. Resistance of $K$. pneumoniae strains to third generation cephalosporins was observed in $9.2 \%$.

$P$. aeruginosa isolates demonstrated remarkable resistance $(>35 \%)$ to cefepime, gentamycin, and cefoperazone. This isolates was most sensitive $(>90 \%)$ to meropenem, imipenem, piperacillin/tazobactam, and ceftazidime. Carbapenem resistance was identified in $8.5 \%$ of Paeruginosa isolates.

\section{DISCUSSION}

This study presents the first estimates of the current prevalence of healthcare associated deep pelvic tissue infection and other infections of the female reproductive tract and antimicrobial resistance of responsible pathogens in Ukrainian women hospitals. The prevalence of healthcare associated deep pelvic tissue infection and other infections of the female reproductive tract was $26.3 \%$. The incidence of infection was: $13.3 \%$ Pelvic abscess or cellulitis, 14.6\% Adnexa utery, 9.5\% Salpingitis, 7.1\% Oophoritis, 12.2\% Parametritis, 4.6\% Chorioamnionitis, and 38.8\% Bacterial Vaginitis. Gynecologic patients had a higher incidence of HAIs compared with pregnant women. Of these cases, $78.6 \%$ were detected after hospital discharge. The prevalence of HAIs in women differed according to the procedure types. In our study gynecologic patients had a higher incidence of HAIs compared with pregnant women. Vaginal delivery represented a low risk of the female reproductive tract infection compared cesarean delivery. Available literatures there are no epidemiologic studies (prevalence or incidence) of different types of healthcare-associated deep pelvic tissue infection and other infections of the female reproductive tract. Therefore, we were unable to compare our results with other studies in other countries.

Microbiological monitoring of the prevalence of etiologic agents of healthcare associated deep pelvic tissue infection and other infections of the female reproductive tract and antimicrobial resistance is necessary to enhance our knowledge of its epidemiology. Therefore, this was the basis for this study. In present study, the predominant pathogens of healthcare associated deep pelvic tissue infection and other infections of the female reproductive tract were E.coli, Enterobacter spp., K. pneumoniae, S.aureus, E.faecalis, P.aeruginosa. Our results was coherent with reports other studies $[7,14,15]$. 
Current international guidelines for the management of pelvic inflammatory disease recommend the prescription of antibiotics for prophylactic and treatment [16-18]. According to the literature, the appointment of an inadequate starting therapy decreases the effectiveness of treatment $[19,20]$. In our study, $26.3 \%$ of patients who were prescribed antibiotics developed reproductive tract infections. Possibly, this is due to the high levels of antimicrobial resistance of causing pathogens of healthcare associated deep pelvic tissue infection and other infections of the female reproductive tract in Ukraine. In present study, overall proportion of extended spectrum betalactamases (ESBL) production among Enterobacteriaceae was $20.8 \%$. The prevalence of ESBL production among E. coli isolates was $24.7 \%$ and among K. pneumoniae isolates was $12.8 \%$. Antimicrobial resistance to third-generation cephalosporins was observed in $12.8 \%$ E.coli isolates and in $9.2 \% \mathrm{~K}$. pneumoniae isolates. Carbapenem resistance was identified in $8.5 \%$ of P.aeruginosa isolates. Methicillin-resistance was observed in $12.9 \%$ of $S$. aureus (MRSA). There is therefore need the treatment and prevention of pelvic infection and other infections of the female reproductive tract with Gram negative bacteria needs to be changed in Ukraine. However, the data are limited and more studies are needed to guide a change in first-line antibiotic treatment or prophylactics.

\section{STUDY LIMITATIONS}

The absence of national surveillance data in Ukraine compelled us to rely entirely on data from the only study prevalence of healthcare associated deep pelvic tissue infection and other infections of the female reproductive tract. The strengths of the study lie in the application of CDC/NHSN methodology. Indicators of HAIs provided by surveillance activities require comparison with adequate reference data to stimulate further infection control actions and to enhance quality of health care. The limitations of this study include in conduct at a in seven (29.2\%) regional women hospitals in Ukraine. Therefore, the results present study not is representative of other hospitals of Ukraine.

\section{CONCLUSIONS}

Healthcare associated deep pelvic tissue infection and other infections of the female reproductive tract in Ukraine is a common occurrence and many cases are caused by pathogens that are resistant to antibiotics. Results this study suggest that the prevention and treatment of pelvic infection and other infections of the female reproductive tract in Ukraine needs to be changed. However, the data are limited and more studies are needed. The present study provides valuable data as a first study for national surveillance of healthcare associated deep pelvic tissue infection and other infections of the female reproductive tract and potential for comparison with data from other countries.

\section{REFERENCES}

1. Ruggeri M., Cannas S., Cubeddu M. et al. Bacterial agents as a cause of infertility in humans. New Microbiol. 2016;39(3):206-209.

2. Mascarenhas M.N., Flaxman S.R., Boerma T. et al. National, regional, and global trends in infertility prevalence since 1990: a systematic analysis of 277 health surveys. PLoS Med. 2012;9(12):e1001356. doi: 10.1371/ journal.pmed.1001356.;

3. Chayachinda C., Rekhawasin T. Reproductive outcomes of patients being hospitalised with pelvic inflammatory disease. J Obstet Gynaecol. 2017 Feb;37(2):228-232. doi: 10.1080/01443615.2016.1234439.

4. Workowski K.A., Bolan G.A. Sexually transmitted diseases treatment guidelines, 2015. MMWR Recommendations and Reports 2015;64(RR03):1-137.

5. Salmanov A., Vozianov S., Kryzhevsky V. et al. Prevalence of healthcareassociated infections and antimicrobial resistance in acute care hospitals in Kyiv, Ukraine. J Hosp Infect. 2019;102(4):431-437. doi: 10.1016/j. jhin.2019.03.008.

6. Ross J. Antibiotic therapy for pelvic inflammatory disease. Cochrane Database Syst Rev. 2017 Apr 24;4(4):CD010285. doi: 10.1002/14651858. CD010285.pub2.

7. Omoregie R., Egbe C.A., Igbarumah I.0. et al. Prevalence and etiologic agents of female reproductive tract infection among in-patients and out-patients of a tertiary hospital in Benin city, Nigeria. N Am J Med Sci. 2010;2(10):473-477. doi:10.4297/najms.2010.2473

8. Quan M. Pelvic inflammatory disease: diagnosis and management. J Am Board Fam Pract. 1994;7(2):110-23

9. Horan T.C., Andrus M., Dudeck M.A. CDC/NHSN surveillance definition of health care-associate 9 infection and criteria for specific types of infections in the acute care setting. Am J Infect Control. 2008;36(5):309332. doi:10.1016/j.ajic.2008.03.002.

10. Salmanov A.G., Vdovychenko S.Y., Litus 0.I. et al. Prevalence of healthcare-associated infections and antimicrobial resistance of the responsible pathogens in Ukraine: Results of a multicenter study (2014-2016). Am J Infect Control. 2019;47(6):e15-e20. doi: 10.1016/j. ajic.2019.03.007.

11. Salmanov A., Vozianov S., Kryzhevsky V. et al. Prevalence of healthcareassociated infections and antimicrobial resistance in acute care hospitals in Kyiv, Ukraine. J Hosp Infect. 2019;102(4):431-437. doi: 10.1016/j. jhin.2019.03.008.

12. Salmanov A.G., Voitok T.G., Maidannyk I.V. et al. Episiotomy infections in the puerperium and antimicrobial resistance of responsible pathogens in Ukraine. Wiad Lek. 2020;73(11):2325-2331. doi: 10.36740/ WLek202011101.

13. Salmanov A.G., Vitiuk A.D., Zhelezov D. et al. Prevalence of postpartum endometritis and antimicrobial resistance of responsible pathogens in Ukraine: results a multicenter study (2015-2017). Wiad Lek. 2020;73(6):1177-1183. doi: 10.36740/WLek202006119.

14. Wójkowska-Mach J., Pomorska-Wesołowska M., Romanik M. et al. Prevalence and Antimicrobial Susceptibility Profiles of Microorganisms Associated with Lower Reproductive Tract Infections in Women from Southern Poland-Retrospective Laboratory-Based Study. Int J Environ Res Public Health. 2021;18(1):335. doi: 10.3390/ijerph18010335.

15. Gregor M., Paterová P., Buchta V. et al. Healthcare-associated infections in gynecology and obstetrics at a university hospital in the Czech Republic. Int J Gynaecol Obstet.2014;126(3):240-3. doi: 10.1016/j.jijgo.2014.04.001.

16. Ross J., Judlin P., Nilas L. European guideline for the management of pelvic inflammatory disease. Int J STD AIDS. 2007;18(10):662-6. doi: 10.1258/095646207782193911. 
17. Sweet R.L. Treatment of acute pelvic inflammatory disease. Infect Dis Obstet Gynecol. 2011;2011:561909. doi: 10.1155/2011/561909.

18. Savaris R.F., Fuhrich D.G., Maissiat ., et al. Antibiotic therapy for pelvic inflammatory disease. Cochrane Database Syst Rev. 2020;8:CD010285. doi: 10.1002/14651858.CD010285.pub3.

19. Laterre P.F., Levy H., Clermont G. et al. Hospital mortality and resource use in subgroups of the Recombinant Human Activated Protein C Worldwide Evaluation in Severe Sepsis (PROWESS) trial. Crit Care Med. 2004;32(11):2207-18. doi: 10.1097/01.ccm.0000145231.71605.d8.

20. Tumbarello M., Sanguinetti M., Montuori E. et al. Predictors of mortality in patients with bloodstream infections caused by extendedspectrum-beta-lactamase-producing Enterobacteriaceae: importance of inadequate initial antimicrobial treatment. Antimicrob Agents Chemother. 2007;51(6):1987-94. doi: 10.1128/AAC.01509-06.

\section{Acknowledgements:}

We would like to thank all the nurses and physicians who contributed to the prevalence surveys.

\section{Funding:}

This work is a fragment of a research study of the Scientific Research Laboratory of Shupyk National Medical Academy of Postgraduate Education (Kyiv, Ukraine). Title: The scientific justification for measures to combat the resistance of microorganisms to antimicrobial drugs in Ukraine on the "One Health" approaches. State Registration Number: 0120U101440. Study period: 2020-2022. This work was funded by the Ministry of Health of Ukraine according to the plan of that research study. The authors did not receive any financial support from the manufacturers of medical instruments and drugs.

\section{ORCID and contributionship:}

Aidyn G. Salmanov: 0000-0002-4673-1154 ${ }^{A, C, D, E, F}$

Svitlana A. Pandei: 0000-0001-9630-7223 B,C,D,F

Lidiya V. Suslikova: 0000-0002-3039-6494 ${ }^{\text {B,C,F }}$

Victor O. Rud: 0000-0002-0768-6477 B,C,D,F

Igor V. Kokhanov - 0000-0001-9083-7178 C,D,F

Victoria Ye. Butska - 0000-0001-6360-394X C,D,F

Alexander G. Tymchenko - 0000-0003-2052-5165 C,D,F

\section{Conflict of interest:}

The Authors declare no conflict of interest

\section{CORRESPONDING AUTHOR}

\section{Aidyn G. Salmanov}

Shupyk National University of Health, St. Dorohozhytska 9, 04112, Kyiv, Ukraine tel: +380667997631

e-mail:mozsago@gmail.com

A - Work concept and design, B - Data collection and analysis, C - Responsibility for statistical analysis, $\mathbf{D}$-Writing the article, $\mathbf{E}$-Critical review, $\mathbf{F}$ - Final approval of the article 